\title{
Late quaternary OSL chronologies from the Qinghai Lake (NE Tibetan Plateau): Intercomparison of quartz and K-feldspar ages to assess the pre-depositional bleaching
}

Long, Hao ; Tsukamoto, Sumiko; Buylaert, Jan-Pieter; Murray, Andrew Sean; Jain, Mayank; Frechen, Manfred

Published in:

Quaternary Geochronology

Link to article, DOI:

10.1016/j.quageo.2018.05.003

Publication date:

2019

Document Version

Peer reviewed version

Link back to DTU Orbit

Citation (APA):

Long, H., Tsukamoto, S., Buylaert, J-P., Murray, A. S., Jain, M., \& Frechen, M. (2019). Late quaternary OSL chronologies from the Qinghai Lake (NE Tibetan Plateau): Intercomparison of quartz and K-feldspar ages to assess the pre-depositional bleaching. Quaternary Geochronology, 49, 159-164.

https://doi.org/10.1016/j.quageo.2018.05.003

\section{General rights}

Copyright and moral rights for the publications made accessible in the public portal are retained by the authors and/or other copyright owners and it is a condition of accessing publications that users recognise and abide by the legal requirements associated with these rights.

- Users may download and print one copy of any publication from the public portal for the purpose of private study or research.

- You may not further distribute the material or use it for any profit-making activity or commercial gain

- You may freely distribute the URL identifying the publication in the public portal 


\section{Accepted Manuscript}

Late quaternary OSL chronologies from the Qinghai Lake (NE Tibetan Plateau): Intercomparison of quartz and K-feldspar ages to assess the pre-depositional bleaching

Hao Long, Sumiko Tsukamoto, Jan-Pieter Buylaert, Andrew Sean Murray, Mayank Jain, Manfred Frechen

PII:

S1871-1014(17)30250-9

DOI:

10.1016/j.quageo.2018.05.003

Reference: QUAGEO 926

To appear in: Quaternary Geochronology

Received Date: 6 December 2017

Revised Date: 18 March 2018

Accepted Date: 8 May 2018

Please cite this article as: Long, H., Tsukamoto, S., Buylaert, J.-P., Murray, A.S., Jain, M., Frechen, M., Late quaternary OSL chronologies from the Qinghai Lake (NE Tibetan Plateau): Inter-comparison of quartz and K-feldspar ages to assess the pre-depositional bleaching, Quaternary Geochronology (2018), doi: 10.1016/j.quageo.2018.05.003.

This is a PDF file of an unedited manuscript that has been accepted for publication. As a service to our customers we are providing this early version of the manuscript. The manuscript will undergo copyediting, typesetting, and review of the resulting proof before it is published in its final form. Please note that during the production process errors may be discovered which could affect the content, and all legal disclaimers that apply to the journal pertain. 
1 Late Quaternary OSL chronologies from the Qinghai Lake (NE Tibetan Plateau): inter-comparison of quartz and K-feldspar ages to assess the pre-depositional bleaching

Hao Long ${ }^{1, *}$, Sumiko Tsukamoto ${ }^{2}$, Jan-Pieter Buylaert ${ }^{3,4}$, Andrew Sean Murray ${ }^{4}$, Mayank Jain ${ }^{3}$, Manfred Frechen ${ }^{4}$

${ }^{1}$ State Key Laboratory of Lake Science and Environment, Nanjing Institute of Geography and Limnology, Chinese Academy of Sciences, 210008 Nanjing, China;

${ }^{2}$ Section of Geochronology, Leibniz Institute for Applied Geophysics (LIAG), D-30655 Hannover, Germany;

${ }^{3}$ Center for Nuclear Technologies, Technical University of Denmark, DTU Ris $\varnothing$ Campus, DK-4000 Roskilde, Denmark;

${ }^{4}$ Nordic Laboratory for Luminescence Dating, Department of Geoscience, Arhus University, DK-4000 Roskilde, Denmark

Abstract: Signal resetting prior to deposition is an important factor for the accuracy of luminescence dating. In this study, resetting of the quartz optically stimulated luminescence (OSL) signal from samples collected from different depositional environments (alluvial, beach, and aeolian sediments) around the Qinghai Lake basin (northeastern Tibetan Plateau) was examined using its inter-comparison with post-IR infrared stimulated luminescence (IRSL) measured at $290^{\circ} \mathrm{C}$ (pIRIR 290 ) from K-feldspar. Dose recovery tests were carried out to test the success of the single aliquot regenerative-dose (SAR) protocol for quartz and feldspar. Additionally, stability tests (first IR temperature plateau and g-values) were

${ }^{*}$ Corresponding author. E-mail addresses: longhao@niglas.ac.cn, lzugeolh@gmail.com (H. Long) 
21

22

performed for the pIRIR 290 . We observe that most of the K-feldspar pIRIR 290 and quartz OSL ages are consistent with each other (within 10\%), suggesting that the quartz OSL signal was well-bleached prior to the deposition. The age of loess samples range between $\sim 13.1$ and $\sim 1.5$ $\mathrm{ka}$, the alluvial sediments between $\sim 35 \mathrm{ka}$ and $\sim 14 \mathrm{ka}$, and beach sediments between 60 and $50 \mathrm{ka}$ (corresponding to early MIS 3). These quartz OSL chronologies suggest a lake highstand during very early MIS 3, a lowstand during late MIS 3 and MIS 2, and widespread loess accumulation through the Holocene in the Qinghai Lake basin.

Keywords: Beach sediments; Bleaching; Quartz OSL; K-feldspar pIRIR; Lake level

\section{Introduction}

During the past decade, the history of lake-level fluctuations on the Tibetan Plateau has been intensively studied for reconstructing past climate changes and regional moisture variations (e.g., Long et al., 2012; Rades et al., 2015), which are considered to have been affected by two key circulation components of global climate systems, i.e., the Asian summer monsoon and the westerlies (An et al., 2012). The exposed beach features and lacustrine sediment remains around closed lake basins are the direct evidence of the past lake-level changes. The late Quaternary history of lake-level fluctuation can be constrained by numerical dating of such sediments using, e.g., optically stimulated luminescence (OSL) and/or radiocarbon dating. OSL, in particular, is increasingly being applied to lacustrine deposits owing to widely available dating materials (quartz and feldspar) and an increased age range compared with the conventionally used radiocarbon dating method (Rhodes, 2011; Buylaert et al., 2013; Long et al., 2015a). 
42

A sufficient signal resetting by daylight exposure prior to burial is one of major prerequisites for reliable age determination using OSL (Aitken, 1998). In some environments, e.g., lacustrine and fluvial, where sediment transport occurs under water with subdued daylight conditions (e.g., Long et al., 2015b), it is possible that incomplete signal resetting (partial bleaching) may give rise to age overestimation. Statistical analysis of single-aliquot (or single-grain) based dose distributions is most commonly applied to evaluate the bleaching level of sediments (e.g., Wallinga, 2002; Bailey and Arnold, 2006); we consider this method to be particularly applicable to young sediments $(<10 \mathrm{ka})$ where partial bleaching dominates over-dispersion. In older materials factors other than partial bleaching, e.g., beta dose heterogeneity, dose response curve shape and measurement error, can play an important role in influencing the dose distribution (Murray and Funder, 2003; Thomsen et al., 2005; Duller, 2008). There seems no widely accepted recipe to identify either intrinsic or extrinsic factors causing overdispersion (e.g., Thomsen et al., 2016). An alternative approach, using comparison of ages derived from signals with different bleaching rates, has been shown to be successful for identifying well-bleached quartz (Murray et al., 2012; Reimann et al., 2015). This approach relies on the fact that the latent infrared stimulated luminescence (IRSL) from feldspar bleaches more slowly than the OSL of quartz (Godfrey-Smith et al., 1988; Buylaert et al., 2012; Murray et al., 2012). Thus, if feldspar IRSL ages (after accounting for anomalous fading) are consistent with quartz OSL ages, then one can be confident that quartz OSL was well reset prior to deposition; presumably also the feldspar ages are not affected by poor bleaching. 
63

In this study, the degree of bleaching of a series of samples collected from different depositional environments (alluvial, lake beach, and aeolian) around the Qinghai Lake basin, northeastern Tibetan Plateau, is examined using a comparison of apparent quartz OSL and feldspar post-IR IRSL (Thomsen et al., 2008; Buylaert et al., 2012) ages. Subsequently, the history of past lake-level variations in the basin is inferred from the OSL chronology.

\section{Samples and experiments}

Qinghai Lake is situated on the northeast of the Tibetan Plateau $\left(37^{\circ} \mathrm{N}, 100^{\circ} \mathrm{E}\right.$, inset of Fig. S1), and is the largest closed-basin lake in China. It has a surface elevation of $3198 \mathrm{~m}$ above sea level (a.s.l), and covers an area of around $4300 \mathrm{~km}^{2}$. A total of 26 samples, collected from nine sites (see Fig. S1 for their locations), originate from a variety of depositional environments (e.g., loess, beach and alluvial sediments). Two representative outcrops are presented in Fig. S2 and S3, showing the highstand beach deposit overlain by loess (QH2) and the aeolian-sand underlain by fluvial sediments (QH11), respectively. The location of luminescence samples and the stratigraphy of all sampled outcrops are shown in Fig. 1.

The upper part of five sections $(\mathrm{QH} 1, \mathrm{QH} 2, \mathrm{QH} 8, \mathrm{QH} 13$, and QH14) are composed of yellowish coarse silt without any horizontal stratification (Fig. 1), which has been interpreted as typical aeolian loess distributed around the Qinghai Lake basin (Lu et al., 2011). The lower part of sections QH2, QH8, QH13 and the sediments from outcrops QH5 and QH16 mainly consist of gravelly sands or well-sorted sands, and are characterized with cross- or inclined bedding structure; this suggests a beach foreshore depositional environment (Tucker, 2003). These beach ridges are almost parallel with the present shoreline. Marked rounded pebbles, 
84

similar to those along the modern shoreline, can be observed in section QH2 (the lower left photo of Fig. S2); these suggest a palaeoshore depositional environment. The materials sampled for OSL dating from the beaches mainly consist of well sorted sands, as shown in Fig. S2 (inset of lower right photo). The sediment samples from sections QH1, QH11, and QH14 were collected from the alluvial fans in close proximity to the (palaeo-) channels. The lower part of section QH1 consists of massive gravelly sands with poor sorting and no obvious structures, probably suggesting a debris flow; a sediment sample LUM-3458 was collected from a sandy lens within this unit. The lower part of section QH11, located on a palaeochannel, is composed of sandy gravel and pebble layers with typical horizontal bedding (Fig. S3), suggesting fluvial (alluvial as well) deposition environment; we collected two OSL samples from a gravelly sand layer. Section QH14 is located in front of a typical alluvial fan; two gravelly sand samples (LUM-3492 and -3493) were obtained from its lower part.

For each sample, both quartz and K-feldspar fractions were extracted for equivalent dose $\left(D_{e}\right)$ measurement. The sediment was first wet sieved to obtain the coarse grain (CG) fraction of 100-200 $\mu \mathrm{m}$, followed by the treatment with $10 \% \mathrm{HCl}$ and $30 \% \mathrm{H}_{2} \mathrm{O}_{2}$ to remove any carbonates and organic matter. Quartz $\left(2.62-2.70 \mathrm{~g} / \mathrm{cm}^{3}\right)$ and K-feldspar $\left(<2.58 \mathrm{~g} / \mathrm{cm}^{3}\right)$ fractions were separated using water-soluble heavy liquid (sodium polytungstate). The quartz grains were etched with $40 \% \mathrm{HF}$ for $60 \mathrm{~min}$ (followed by an $\mathrm{HCl}$ rinse) to remove the outer alpha-irradiated layer of the quartz grains and eliminate potential feldspar contamination.

Luminescence measurements were made on Ris $\varnothing$ readers (Bøtter-Jensen et al., 2010) equipped with a built-in beta source calibrated to give a known dose rate to quartz, and a 
105

106

107

classic stimulation and detection head consisting of blue $(\sim 40 \mathrm{~nm})$ and infrared $(\sim 870 \mathrm{~nm})$ light emitting diodes. Quartz OSL was detected through a 7.5-mm-thick Hoya U-340 filter, and IRSL from K-feldspar was detected through a combination of Corning BG-39 and BG-3 filters in the UV/blue light spectrum. Due to a weak signal intensity, large aliquots (6 mm) were mounted on stainless steel discs using silicone oil for quartz OSL measurement, and the conventional single aliquot regenerative (SAR) protocol was used to determine $\mathrm{D}_{\mathrm{e}}$ (Murray and Wintle, 2000) with a preheat $260^{\circ} \mathrm{C}$ for $10 \mathrm{~s}$, a cutheat of $220^{\circ} \mathrm{C}$, and OSL stimulation at $125^{\circ} \mathrm{C}$; the purity of the quartz extracts was checked by the OSL IR depletion ratio (Duller, 2003). Between 15 and 35 aliquots were measured for $D_{e}$ estimation using quartz. Aliquot size was $\sim 2 \mathrm{~mm}$ diameter for K-feldspar fractions. K-feldspar grains were measured using a post-IR IRSL protocol (Thiel et al., 2011; Buylaert et al., 2012) in which the preheat temperature was raised to $320^{\circ} \mathrm{C}$ for $60 \mathrm{~s}$. An IR stimulation at $290^{\circ} \mathrm{C}$ (pIRIR 290 ) was inserted after each IR stimulation at $50^{\circ} \mathrm{C}\left(\mathrm{IR}_{50}\right) ; 8-15$ discs were measured for the $\mathrm{D}_{\mathrm{e}}$ estimation from K-feldspar. The purity of the extracted K-feldspar fractions (three aliquots for each sample) was checked by X-ray fluorescence (XRF) measurements using the Risø XRF attachment mounted on the reader (Kook et al., 2012).

The concentration of uranium $(\mathrm{U})$, thorium $(\mathrm{Th})$, and potassium $(\mathrm{K})$ was determined by neutron activation analysis (NAA) for all samples. In addition, 10 samples were also measured by high-resolution gamma spectrometry (Murray et al., 1987) for cross-comparison. NAA method utilizes small quantity of material for measurement, and thus the dose rate obtained from NAA may not be appropriate when sediment is inhomogeneous. To decrease this uncertainty as much as possible, we collected the materials surrounding the OSL 
127 sampling tube within a radius of $30 \mathrm{~cm}$, rather than only relying on material from the tube, for

128 dose rate measurement. The material was then ground; $\sim 5 \mathrm{~g}$ of the homogenised material was

129 used for NAA analysis and 200-300 g for gamma spectrometry measurement. The conversion

130 factors of Guérin et al. (2011) and the $\beta$-attenuation factors after Mejdahl (1979) are used to

131 calculate the external $\beta$ - and $\gamma$-dose rates. A water content of $10 \%( \pm 10 \%)$ was assigned to

132 correct the $\beta$ - and $\gamma$-dose rates for the water attenuation. For the internal dose rate calculation

133 of K-feldspar, a K concentration of $12.5 \pm 0.5 \%$ (Huntley and Baril, 1997) and a Rb content

134 of $400 \mu \mathrm{g} / \mathrm{g}$ (Huntley and Hancock, 2001) are assumed. The cosmic ray dose rate was

135 estimated for each sample as a function of depth, altitude, and geomagnetic latitude according

136 to Prescott and Hutton (1994).

137 3. Results and discussion

$138 \quad 3.1$ Quartz OSL

139 To assess the performance of the SAR protocol, and to choose suitable thermal treatments for

140 our samples, we carried out a dose recovery preheat-plateau test for a beach sample

141 (LUM-3461, given dose=132 Gy) and a loess sample (LUM-3474, given dose =22 Gy). The

142 preheat temperatures ranged from $200^{\circ} \mathrm{C}$ to $300^{\circ} \mathrm{C}$ with $20^{\circ} \mathrm{C}$ increments, while the cutheat

143 was always $40^{\circ} \mathrm{C}$ below the preheat temperature. Three aliquots for each temperature were

144 measured. The results of the dose recovery test for the two samples are shown in Fig. S4a.

145 The dose recovery ratio of both samples is independent of the preheat temperatures (within

$14610 \%$ of unity); the recycling ratio and recuperation value for all samples are satisfactory

147 (except at $300^{\circ} \mathrm{C}$ ). Fig. S4b shows a normalized natural OSL curve and a dose-response curve 
148

149

150

151

152

153

154

155

156

157

158

159

160

161

162

163

164

165

166

167

168

169

for sample LUM-3461; this sample exhibits a typical fast-component dominated OSL decay curve (e.g., Jain et al., 2003). The first $0.48 \mathrm{~s}$ of the stimulation curve was used for OSL signal integration, after subtracting the background signal derived from the subsequent 0.48 $1.6 \mathrm{~s}$ integral to minimize contamination from the medium and slow components (Ballarini et al., 2007; Cunningham and Wallinga, 2010).

However, it is noted that most aliquots/samples show OSL IR depletion ratios of $<0.9$; the deviation of this ratio from unity is probably due to feldspar contamination. Fig. S5 shows the $\mathrm{D}_{\mathrm{e}}$ values of individual aliquots of two young samples (LUM-3504 and LUM-3505) and two relatively old samples (LUM-3461 and LUM-3467), plotted as a function of their OSL IR depletion ratio. LUM-3504 shows no correlation, whereas LUM-3505 shows a slight tendency for a negative correlation $\left(\mathrm{R}^{2}=0.181\right)$. In contrast, there is a slightly positive correlation between $D_{e}$ and OSL IR depletion ratio for the two old samples, probably suggesting that feldspar contamination tends to affect more significantly the older samples (Tsukamoto and Rades, 2016). However, the ratio of K-feldspar and quartz $\mathrm{D}_{\mathrm{e}}$ values, both determined using the same blue SAR protocol, is $>1$ for these two samples, which is evidence that feldspar contamination cannot cause quartz OSL $D_{e}$ underestimation. Similar phenomenon has also been reported in marine sediments from the Okhotsk Sea (Sugisaki et al., 2012). To further confirm this interpretation, three samples (LUM-3457, -3458, and -3461) were measured with protocols deliberately rejecting the contamination signal: (i) inserting IR bleaching at $125^{\circ} \mathrm{C}$ for $100 \mathrm{~s}$, before OSL stimulation (i.e., post-IR OSL, Banerjee et al., 2001; Jain and Singhvi, 2001), and (ii) using pulsed OSL after IR bleaching at $125^{\circ} \mathrm{C}$ for 100 s (i.e., post-IR POSL, Thomsen et al., 2008; Ankjærgaard et al., 2010) instead 
170

171

172

173

174

175

176

177

178

179

180

181

182

183

of the continuous wave (CW) OSL. Fig. 2 shows the $\mathrm{D}_{\mathrm{e}}$ comparison for post-IR CW-OSL or post-IR POSL with the standard blue light SAR OSL. The results do not show significant differences among different protocols, which suggests a negligible impact of feldspar contamination on the dose estimates.

\subsection{K-feldspar pIRIR}

K-feldspar fraction is normally extracted by density separation, but few studies check the validity of this method. In this study, the XRF analysis on the K-feldspar purity showed that the extracted fraction by density separation is dominated with K-feldspar (Fig. S6). The average $\mathrm{K}$ concentration of the aliquots in our XRF measurements is $12.21 \pm 0.03 \%(\mathrm{n}=48)$, very close to the assumed value of $12.5 \pm 0.5 \%$ from Huntley and Baril (1997).

A dose recovery test for the pIRIR 290 was done by adding different laboratory doses (18 to $1150 \mathrm{~Gy}$ ) to a young beach sample (LUM-3505), and keeping the test dose at the level of 30\% of the given dose (Yi et al., 2016). It can be seen that the dose recovery ratios are satisfactory for this sample at least up to $\sim 830$ Gy (Fig. 3).

In order to investigate signal stability in the pIRIR protocol, two samples (loess sample LUM-3457 and beach sample LUM-3489) were used to measure the first IR stimulation temperature plateau (Buylaert et al., 2012). Fig. 4 shows $D_{e}$ values as a function of prior IR stimulation temperature for LUM-3457 and LUM-3489, respectively. It appears that the obtained $D_{e}$ values in these two samples are not very sensitive to the choice of the first IR 
189

190

191

192

193

194

195

stimulation temperature. As a result, we utilized the IIRIR $_{290}$ protocol with a first IR stimulation temperature of $50^{\circ} \mathrm{C}$ to measure the dose for all samples.

Various studies already showed that the pIRIR $_{290}$ signal does not require fading correction to give accurate dose estimates (e.g., Buylaert et al., 2012). To confirm whether this conclusion also applies to our study, two samples (LUM-3461 and LUM-3505) were used to determine the anomalous fading rates (g-values) of pIRIR $_{290}$ signals. Three aliquots from each sample were measured following the method described by Auclair et al. (2013); the g-value of each aliquot was obtained by linear regression for the sensitivity-corrected pIRIR signals as a function of logarithmic normalized delay time (Fig. 5). The g-values of pIRIR 290 signals range within $0-1 \% /$ decade for the younger sample LUM-3505 and 1-1.5\%/decade for the older sample LUM-3461. Based on the correction method of Huntley and Lamothe (2001), the fading corrected pIRIR $_{290}$ age of sample LUM-3461 was calculated to $72.9 \pm 6.0 \mathrm{ka}$, which is consistent with the fading uncorrected age $(65.5 \pm 4.8 \mathrm{ka})$ within $1-\sigma$ uncertainty. These fading rates (less than $\sim 1.5 \% /$ decade) are thus considered to be very small, and we did not correct for the apparent instability; this is also in line with the study of Roberts (2012). Therefore, the uncorrected pIRIR 290 signals were used for luminescence age calculation in this study.

\subsection{Dose rates and comparison of quartz and K-feldspar ages}

The concentrations of $\mathrm{U}$, Th and $\mathrm{K}$, determined by NAA method for all samples, are presented in Table S1. The inter-comparison of NAA and gamma spectrometry for 10 samples gives mutually consistent results from the two methods (Fig. 6). These data confirm the reliability of NAA measurements for dose rate estimation. 
210 We also collected and measured a modern beach sample (LUM-3478) with an expected dose

211 close to zero. The quartz $\mathrm{D}_{\mathrm{e}}$ values varied from $\sim 0.6 \mathrm{~Gy}$ to $\sim 66 \mathrm{~Gy}$ for different aliquots of

212 this sample (Fig. S7), implying that not all grains were reset by daylight. However, the mean

213 OSL dose from the modern sample is approximately 5.4 Gy (corresponding to about $1.8 \mathrm{ka}$ ),

214 suggesting that any residual dose will not affect the highstand beach ages in our study as they

215 are >50 ka. Furthermore, modern samples should only be considered as the worst case

216 scenario since the net probability of sediment bleaching is a function of its preservation

217 potential in the stratigraphic record (Jain et al., 2004).

218 The age estimates from both quartz and K-feldspar are listed in Table S1, and their

219 comparison is shown in Fig. 7. The quartz OSL ages are generally in good agreement (within

220 2- $\sigma$ uncertainty) with K-feldspar pIRIR 290 ages. For three very young samples (LUM-3473,

$221-3504$, and -3505) the relative age difference is larger (inset in Fig. 7), presumably because of

222 the unbleachable or very hard to bleach residual signal of the pIRIR ${ }_{290}$, often around $\sim 4-5 \mathrm{~Gy}$

223 (Buylaert et al., 2012); such residual dose may cause an age offset of $\sim 1$ ka. There seems to

224 be some overestimation in pIRIR 290 ages compared to quartz OSL for three alluvial samples

225 (LUM-3479, -3492, and -3493), whereas the remaining alluvial samples (LUM-3458 and

$226-3480)$ show an excellent age agreement for the two signals. Since the bleaching rate of

227 pIRIR290 is orders of magnitude lower than that of quartz OSL, a general concordance

228 between the ages derived from the two signals suggests that quartz OSL signals were

229 sufficiently reset prior to deposition for all the three environments. Thus, the quartz ages were

230 used for the following discussion on the lake levels. 
231

232

233

234

235

236

237

238

239

240

241

242

243

244

245

\subsection{Implication for the lake-levels of Qinghai Lake basin}

The highstand beach sediments, $\sim 30-50 \mathrm{~m}$ high above the modern lake level, from five sections (i.e., QH2, QH5, QH7, QH8, and QH13) were consistently dated to 75-50 ka within uncertainties (Fig. 1 and Table S1). If we look at the dates of these beaches closely, they are mainly centred around $60 \mathrm{ka}$, corresponding to the early Marine Isotope Stage 3 (MIS 3). Another two sediment samples from beach QH16 yielded very young ages ( $\sim 0.5 \mathrm{ka}$ and 0.3 ka), suggesting a very recent lake highstand of up to $\sim 8 \mathrm{~m}$ above modern lake level. The alluvial sediments from three outcrops (QH1, QH11, and QH14) yield ages ranging between 35 and $14 \mathrm{ka}$, equivalent to the time period of late MIS 3 and MIS 2. The alluvial sediments should be at higher altitude compared to the ambient lake level; thus, the lake must have experienced a lowstand during late MIS 3 to MIS 2. The uppermost loess units from five sections (QH1, QH2, QH8, QH13, and QH14) yielded stratigraphically consistent ages ranging from $\sim 13 \mathrm{ka}$ to $\sim 1 \mathrm{ka}$, suggesting an extensive loess accumulation during the Holocene in the Qinghai Lake basin.

Generally, our dating results suggest an early MIS 3 highstand and a lowstand during late MIS 3 and MIS 2. This seems to contradict the results of Madsen et al. (2008) suggesting a highstand of $\sim 20-60 \mathrm{~m}$ above the modern lake level during late MIS 5 through OSL dating using multiple aliquot regeneration (MAR) protocol. This large age difference, early MIS 3 to MIS 5, between their and our results, respectively, may perhaps reflect that this early study using MAR protocol requires further investigation (e.g., MAR dose recovery test). Our data confirmed the reports of Liu et al. (2010) who mainly used the quartz SAR dating of the 
252

253

254

middle grain-size fraction. It is worth noting that our quartz OSL chronologies of early MIS 3

highstand in Qinghai Lake are in contrast to the extensively reported lake highstand events during the late MIS 3. The latter are based on numerous radiocarbon ages of lake shorelines and terraces from the Tibetan Plateau and adjacent areas (e.g., Shi et al., 2001; Zhang et al., 2004).

\section{Conclusion}

Both quartz and K-feldspar extracts have been used for dating a series of sediment samples, representing different depositional environments (e.g., lacustrine beach, alluvial, and aeolian) in the Qinghai Lake basin. Our results show that the quartz OSL ages are consistent with the K-feldspar pIRIR 290 ages (within $10 \%$ ); thus quartz OSL was sufficiently reset prior to deposition in all the environments. We infer lake level highstands during the very early MIS 3 and recent times, low lake levels during late MIS 3 and MIS 2, and extensive loess sedimentation during the Holocene.

\section{Acknowledgment:}

This research was supported by the Program of Global Change and Mitigation (grants no.2016YFA0600502), the National Science Foundation of China (grant No. 41472144), and the Youth Innovation Promotion Association CAS (grant No. 2015251). We thank many helping hands from Sabine Mogwitz, Petra Posimowski, Vicki Hansen, Saiko Sugisaki, Louise Helsted for laboratory work, and Linhai Yang, Mingliang Tan, Hongyi Cheng for field 
271 sampling. We appreciate the helpful suggestions from an anonymous reviewer and Dr.

272 Michael Kenzler.

\section{References:}

274 Aitken, M.J., 1998. An Introduction to Optical Dating. Oxford University Press: Oxford.

275 An, Z.S., Colman, S.M., Zhou, W.J., Li, X.Q., Brown, E.T., Jull, A.J.T., Cai, Y.J., Huang, Y.S., Lu, X.F.,

Ankjærgaard, C., Jain, M., Thomsen, K.J., Murray, A.S., 2010. Optimising the separation of quartz and feldspar optically stimulated luminescence using pulsed excitation. Radiat. Meas. 45, 778-785.

Auclair, M., Lamothe, M., Huot, S., 2003. Measurement of anomalous fading for feldspar IRSL using SAR. Radiat. Meas. 37, 487-492.

Bailey, R.M., Arnold, L.J., 2006. Statistical modelling of single grain quartz $\mathrm{D}_{\mathrm{e}}$ distributions and the assessment of procedures for estimating burial dose. Quat. Sci. Rev. 25, 2475-2502.

Ballarini, M., Wallinga, J., Wintle, A.G., Bos, A.J.J, 2007. A modified SAR protocol for optical dating of individual grains from young quartz samples, Radiat. Meas., 42, 360-369.

Banerjee, D., Murray, A.S., Bøtter-Jensen, L., Lang, A., 2001. Equivalent dose estimation using a single aliquot of polymineral fine grains. Radiat. Meas. 33, 73-94.

Bøtter-Jensen, L., Thomsen, K.J., Jain, M., 2010. Review of optically stimulated luminescence (OSL) 
292

293

Buylaert, J.P., Thiel, C., Murray, A.S., Vandenberghe, D.A.G., Yi, S., Lu, H., 2011. IRSL and post-IR IRSL residual doses recorded in modern dust samples from the Chinese Loess Plateau. Geochronometria 38, 432-440.

Buylaert, J.-P., Jain, M., Murray, A.S., Thomsen, K.J., Thiel, C., Sohbati, R., 2012. A robust feldspar luminescence dating method for Middle and Late Pleistocene sediments. Boreas 41, 435-451.

Buylaert, J.P., Murray, A.S., Gebhardt, A.C., Ohlendorf, C., Thiel, C., Wastegård, S., Zolitschka, B., The PASADO Science Team, 2013. Luminescence dating of the PASADO core 5022-1D from Laguna PotrokAike (Argentina) using IRSL signals from feldspar. Quat. Sci. Rev. 71, 70-80.

Cunningham, A.C., Wallinga, J., 2010. Selection of integration time intervals for quartz OSL decay curves. Quat. Geochronol. 5, 657-666.

Duller, G.A.T., 2003. Distinguishing quartz and feldspar in single grain luminescence measurements. Radiat. Meas. 37, 161-165.

Duller, G.A.T., 2008. Single-grain optical dating of quaternary sediments: why aliquot size matters in luminescence dating. Boreas 37, 589-612.

Kook, M.H., Lapp, T., Murray, A.S., Thiel, C., 2012. A Ris $\varnothing$ XRF attachment for major element analysis of aliquots of quartz and feldspar separates. Abstract book for UK Luminescence and ESR Meeting, p. 37.

Godfrey-Smith, D.L., Huntley, D.J., Chen, W.H., 1988. Optically dating studies of quartz and feldspar sediment extracts. Quat. Sci. Rev. 7, 373-380.

Huntley, D.J., Baril, M.R., 1997. The K content of the K-feldspars being measured in optical dating or in thermoluminescence dating. Ancient TL 15, 11-13.

Huntley, D.J., Hancock, R.G.V., 2001. The Rb contents of the K-feldspars being measured in optical 
dating. Ancient TL 19, 43-46.

Huntley, D.J., Lamothe, M., 2001. Ubiquity of anomalous fading in K-feldspars and the measurement and correction for it in optical dating. Can. J. Earth Sci. 38, 1093-1106.

Jain, M., Singhvi, A.K., 2001. Limits to depletion of blue-green light stimulated luminescence in feldspars: implications for quartz dating. Radiat. Meas. 33, 883-892.

Jain, M., Murray, A.S., Bøtter-Jensen, L., 2003. Characterisation of blue-light stimulated luminescence components in different quartz samples: implications for dose measurement. Radiat. Meas. 37, $441-449$.

Jain, M., Murray, A.S., Bøtter-Jensen, L., 2004. Optically stimulated luminescence dating: how significant is incomplete light exposure in fluvial environments? Quaternaire 15, 143-157.

Liu, X., Lai, Z., Fan, Q., Long, H., Sun, Y., 2010. Timing for high lake levels of Qinghai Lake in the Qinghai-Tibetan Plateau since the last interglaciation based on quartz OSL dating. Quat. Geochronol. 5, 218-222.

Long, H., Lai, Z., Fuchs, M., Zhang, J., Li, Y., 2012. Timing of Late Quaternary palaeolake evolution in Tengger Desert of northern China and its possible forcing mechanisms. Glob. Planet. Change 92-93, 119-129.

Long, H., Shen, J., Wang, Y., Gao, L., Frechen, M., 2015a. High resolution OSL dating of a late Quaternary sequence from Xingkai Lake (NE Asia): Chronological challenge of the "MIS3a Mega-paleolake" hypothesis in China. Earth Planet. Sci. Lett. 428, 281-292.

Long, H., Haberzettl, T., Tsukamoto, S., Shen, J., Kasper, T., Daut, G., Zhu, L., Mäusbacher, R., Frechen, M., 2015b. Luminescence dating of lacustrine sediments from Tangra Yumco (southern Tibetan Plateau) using post-IR IRSL signals from polymineral grains. Boreas 44, 139-152. 
336

Lu, H.Y., Zhao, C.F., Mason, J., Yi, S.W., Zhao, H., Zhou, Y.L., Ji, J.F., Swinehart, J., Wang, C.M., 2011. Holocene climatic changes revealed by aeolian deposits from the Qinghai Lake area (northeastern Qinghai-Tibetan Plateau) and possible forcing mechanisms. Holocene 21, 297-304.

Madsen, D.B., Ma, H.Z., Rhode, D., Brantingham, P.J., Forman, S.L., 2008. Age constraints on the Late Quaternary evolution of Qinghai Lake, Tibetan Plateau. Quat. Res. 69, 316-325.

Mejdahl, V., 1979. Thermoluminescence dating: Beta attenuation in quartz grains. Archaeometry 21, $61-73$.

Murray, A.S., Marten, R., Johnston, A., Martin, P., 1987. Analysis for naturally occurring radionuclides at environmental concentrations by gamma spectrometry. J. Radioanal. Nuclear Chemistry 115, $263-288$.

Murray, A.S., Wintle, A.G., 2000. Luminescence dating of quartz using an improved single-aliquot regenerative-dose protocol. Radiat. Meas. 32, 57-73.

Murray, A.S., Funder, S., 2003. Optically stimulated luminescence dating of a Danish Eemian coastal marine deposit: a test of accuracy. Quat. Sci. Rev. 22, 10-13.

Murray, A.S., Thomsen, K.J., Masuda, N., Buylaert, J.P., Jain, M., 2012. Identifying well-bleached quartz using the different bleaching rates of quartz and feldspar luminescence signals. Radiat. Meas. 47, 688-695.

Prescott, J.R., Hutton, J.T., 1994. Cosmic ray contributions to dose rates for luminescence and ESR dating: large depths and long-term variations. Radiat. Meas. 23, 497-500.

Rades, E.F., Tsukamoto, S., Frechen, M., Xu, Q., Ding, L., 2015. A lake-level chronology based on feldspar luminescence dating of beach ridges at Tangra Yum Co (southern Tibet). Quat. Res. 83, $469-478$ 
358

359

360

361

362

363

364

365

366

367

368

369

370

371

372

373

374

375

Reimann, T., Notenboom, P.D., Schipper. M.A.S., Wallinga, J., 2015. Testing for sufficient signal resetting during sediment transport using a polymineral multiple-signal luminescence approach. Quat. Geochronol. 25, 26-36.

Rhodes, E.J., 2011. Optically stimulated luminescence dating of sediments over the past 200,000 years. Annu. Rev. Earth Planet. Sci. 39, 461-488.

Roberts, H.M., 2012. Testing Post-IR IRSL protocols for minimizing fading in feldspars, using Alaskan loess with independent chronological control. Radiat. Meas. 47, 716-724.

Shi, Y.F., Yu, G., Liu, X.D., Li, B.Y., Yao, T.D., 2001. Reconstruction of the 30-40 ka BP enhanced Indian monsoon climate based on geological records from the Tibetan Plateau. Palaeogeogr. Palaeoclimatol. Palaeoecol. 169, 69-83.

Sugisaki, S., Buylaert, J.P., Murray, A.S., Harada, N., Kimoto, K., Okazaki, Y., Sakamoto, T., Iijima, K., Tsukamoto, S., Miura, H., Nogi, Y., 2012. High resolution optically stimulated luminescence dating of a sediment core from the southwestern Sea of Okhotsk. Geochem. Geophys. Geosyst. 13, $1-20$.

Thiel, C., Buylaert, J.-P., Murray, A., Terhorst, B., Hofer, I., Tsukamoto, S., Frechen, M., 2011. Luminescence dating of the Stratzing loess profile (Austria) -Testing the potential of an elevated temperature post-IR IRSL protocol. Quat. Int. 234, 23-31.

Thomsen, K.J., Murray, A.S., Bøtter-Jensen, L., 2005. Sources of variability in OSL dose measurements using single grains of quartz. Radiat. Meas. 39, 47-61.

Thomsen, K.J., Jain, M., Murray, A.S., Denby, P.M., Roy, N., Botterjensen, L., 2008. Minimizing feldspar OSL contamination in quartz UV-OSL using pulsed blue stimulation. Radiat. Meas. 43, $752-757$. 
380

381

382

383

384

385

386

387

388

389

390

391

392

393

394

395

396

397

398

399

400

Thomsen, K.J., Murray, A.S., Buylaert, J.P., Jain, M., Hansen, J.H., Aubry, T., 2016. Testing single-grain quartz OSL methods using sediment samples with independent age control from the Bordes-Fitte rockshelter (Roches d'Abilly site, Central France). Quat. Geochronol. 31, 77-96.

Tsukamoto, S., Rades, E.F., 2016. Performance of pulsed OSL stimulation for minimizing the feldspar signal contamination in quartz samples. Radiat. Meas. 84, 26-33.

Tucker, M.E., 2003. Sedimentary rocks in the field ( $3^{\text {rd }}$ ed.). John Wiley \& Sons Ltd: West Sussex, UK.

Wallinga, J., 2002. Optically stimulated luminescence dating of fluvial deposits: a review. Boreas 31, $303-322$.

Wintle, A.G., Murray, A.S., 2006. A review of quartz optically stimulated luminescence characteristics and their relevance in single aliquot regeneration dating protocols. Radiat. Meas. 41, 369-391.

Yi, S., Buylaert, J.P., Murray, A.S., Lu, H., Thiel, C., Zeng, L., 2016. A detailed post-IR IRSL dating study of the Niuyangzigou loess site in northeastern China. Boreas 45, 644-657.DOI $10.1111 /$ bor. 12185

Zhang, H.C., Peng, J.L., Ma, Y.Z., Chen, G.J., Feng, Z.D., Li, B., Fang, H.F., Chang, F.Q., Lei, G.L., Wünnemann, B., 2004. Late Quaternary palaeolake levels in Tengger Desert, NW China. Palaeogeogr. Palaeoclimatol. Palaeoecol. 211, 45-58.

\section{Captions of figures and table:}

Fig. 1. Sketched stratigraphy of nine investigated sections, and locations and quartz OSL ages of samples.

Fig. 2. Comparison of equivalent doses determined by different protocols for three samples.

Fig. 3. Dose recovery test by adding different doses ( 10 to $\sim 1000 \mathrm{~Gy})$ on natural sample LUM-3505. 
401

402

403

404

405

406

407

408

409

410

411

412

413

414

415

416

417

418

419

420

Fig. 4. Dependence of $D_{e}$ on prior IR stimulation temperature for samples LUM-3457 (test dose=13.2 Gy) (a) and LUM-3489 (test dose=110 Gy) (b).

Fig. 5. Results of g-values (\%/decade) of pIRIR 290 signals for two samples, LUM-3505 (left) and LUM-3461 (right). Different colours show three different aliquots for each sample.

Fig. 6. Comparison of nuclides' concentration determined by NAA and gamma spectrometry.

Fig. 7. Comparison of luminescence ages derived from quartz OSL and K-feldspar pIRIR 290 signals.

Fig. S1. Study area and locations of sections investigated in this study (different number shows different sites, e.g., No. 1 denotes section QH1; No. 2 denotes section QH2, and No. 11 shows section QH11...).

Fig. S2. Field photo showing the representative beach section $(\mathrm{QH} 2)$ and locations of four samples.

Fig. S3. Field photo showing the representative alluvial section (QH11) and locations of two samples.

Fig. S4. (a) Dose recovery tests for samples LUM-3461 and LUM-3474. Bleaching involved two $40 \mathrm{~s}$ blue LED bleach at room temperature separated by a $10000 \mathrm{~s}$ pause. Three aliquots for each temperature were measured and uncertainties represent one standard error; (b) A normalized decay curve and a growth curve for sample LUM-3461.

Fig. S5. $\mathrm{D}_{\mathrm{e}}$ values against OSL IR depletion ratios for samples LUM-3504, -3505, -3461, and -3467.

Fig. S6. Ternary plot showing the purity of the K-feldspar extracts.

Fig. S7. Quartz OSL dose distribution of a modern beach sample LUM-3478.

Table. S1. Dating results for all samples. De values are calculated as simple arithmetic means and quoted with one standard error. 
Fig. 1

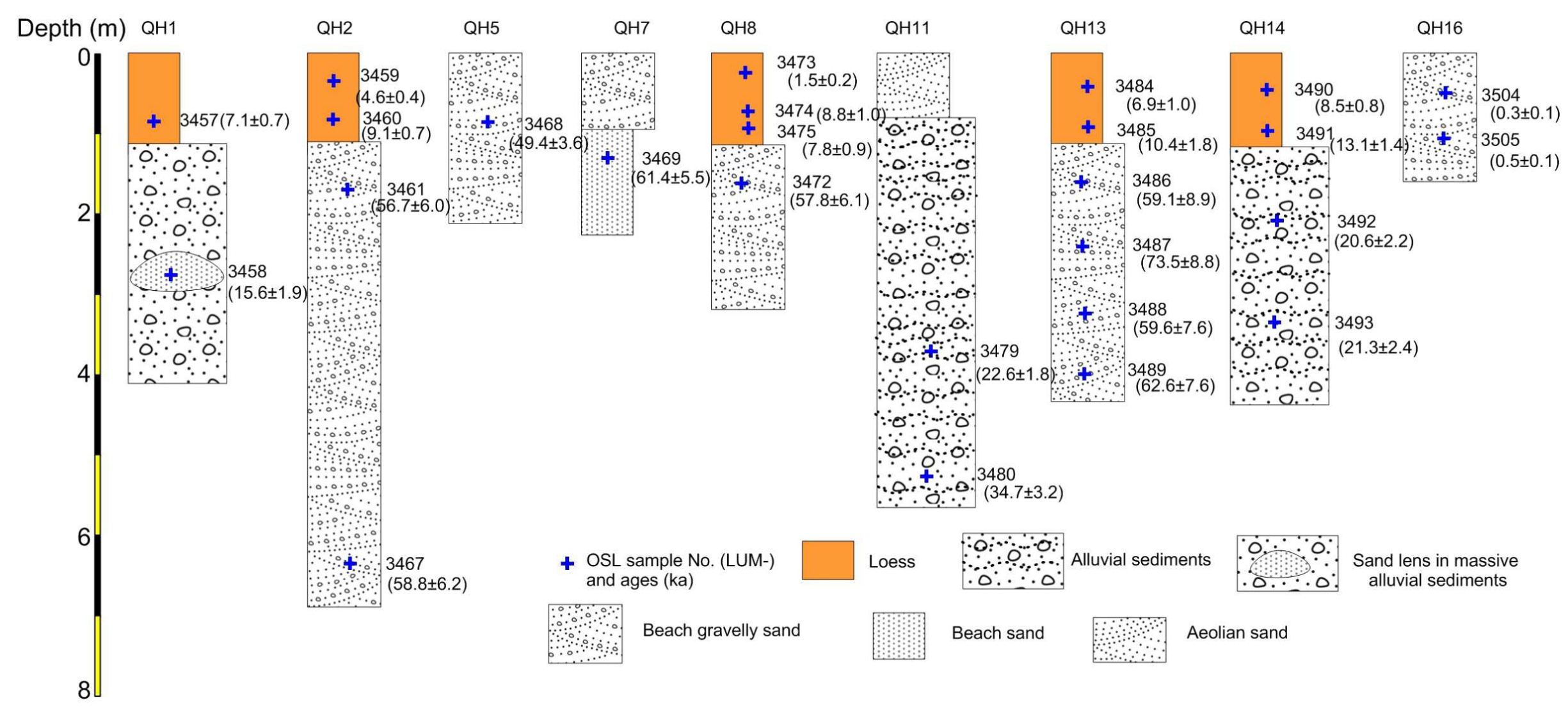


Fig. 2

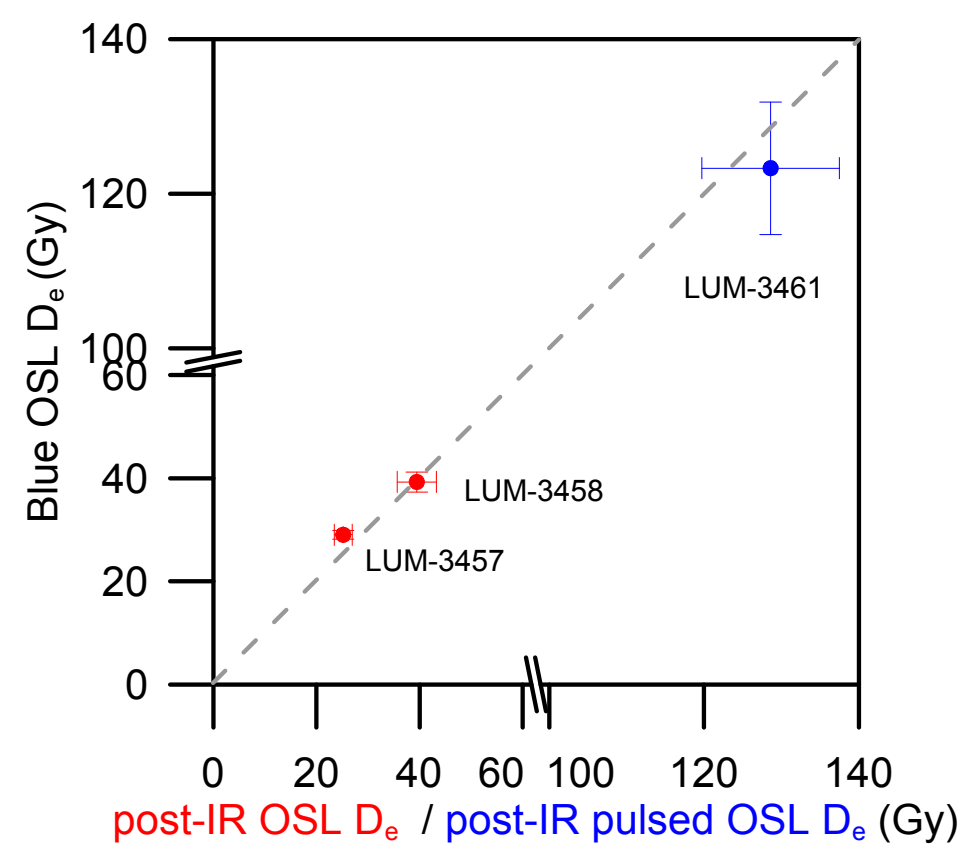


Fig. 3

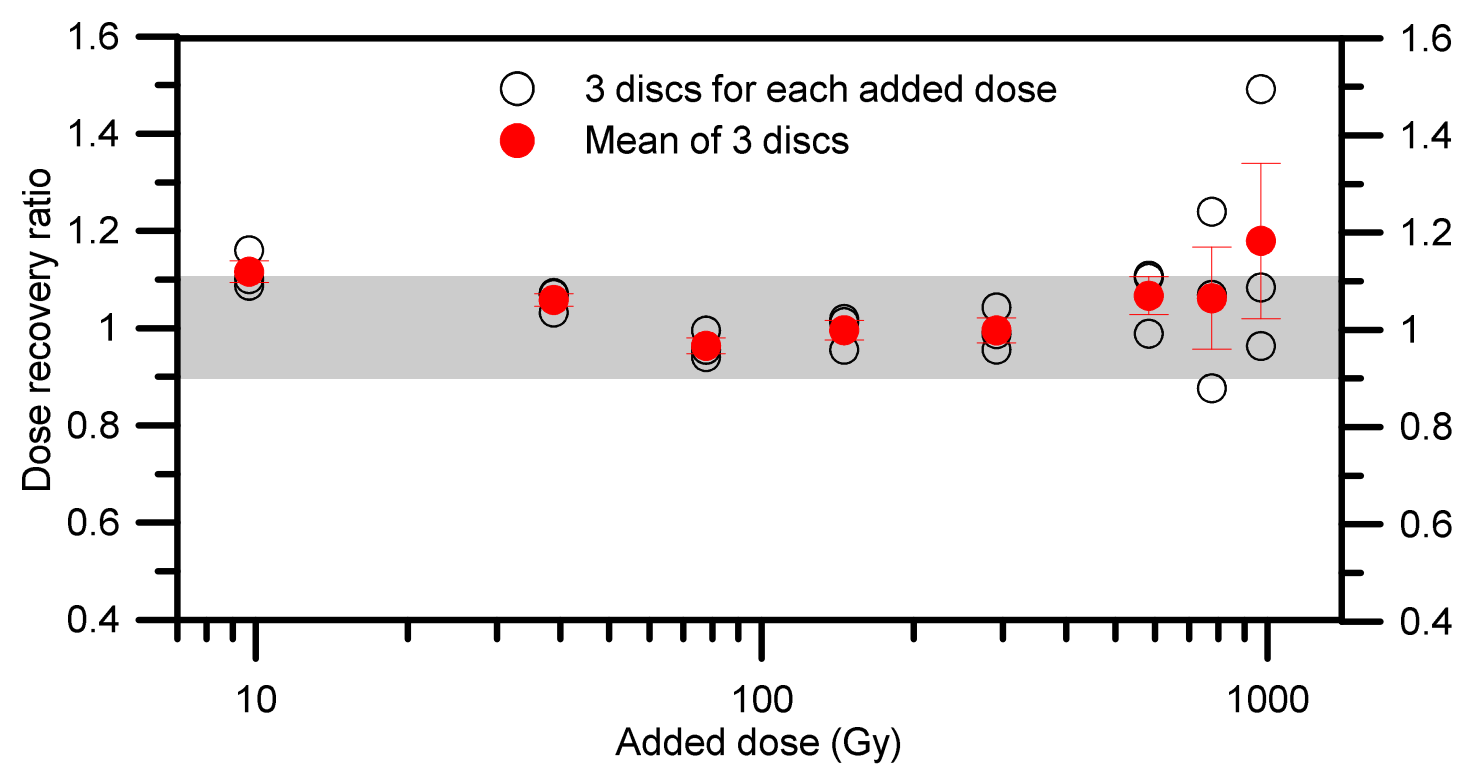


Fig. 4
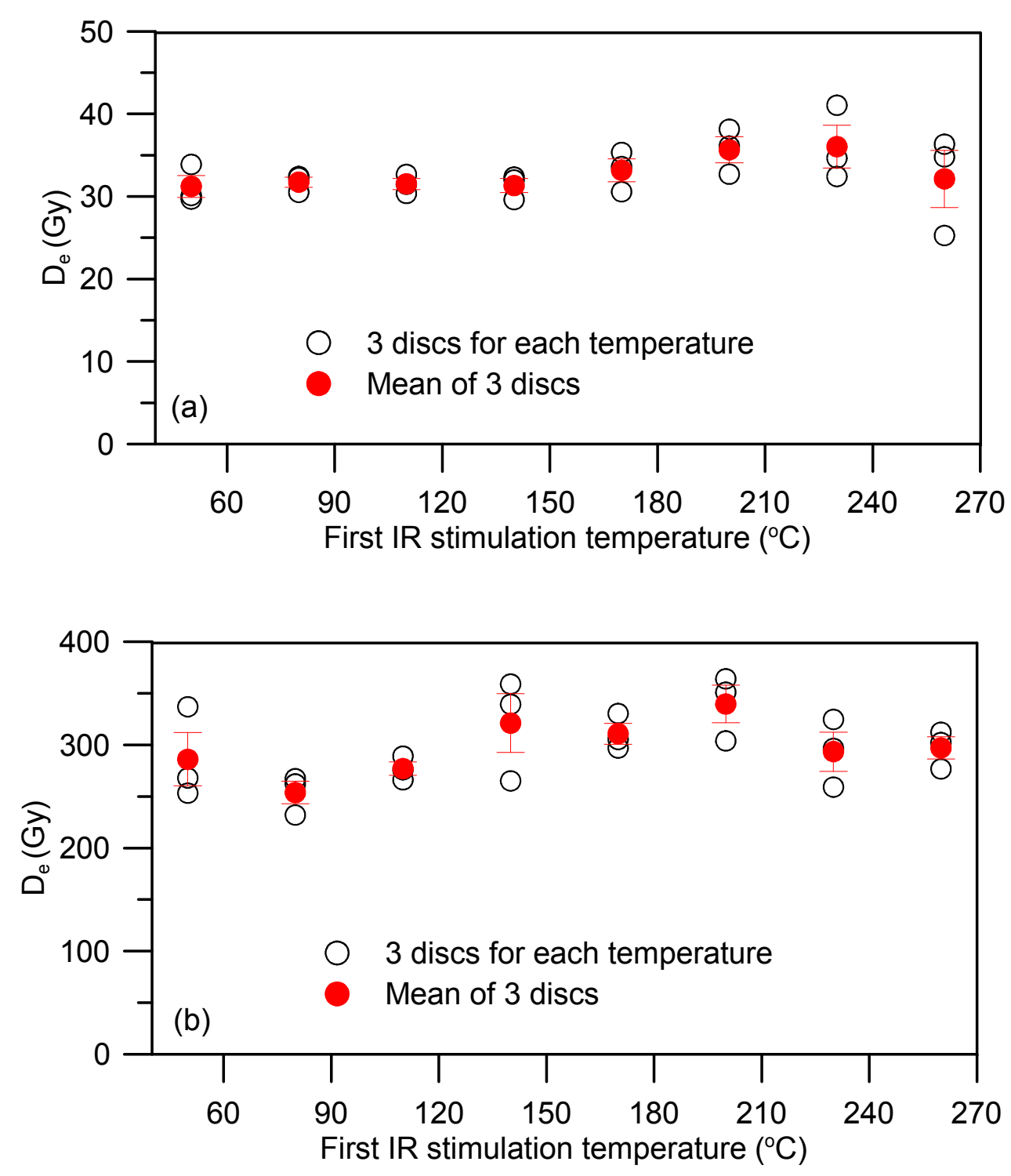
Fig. 5
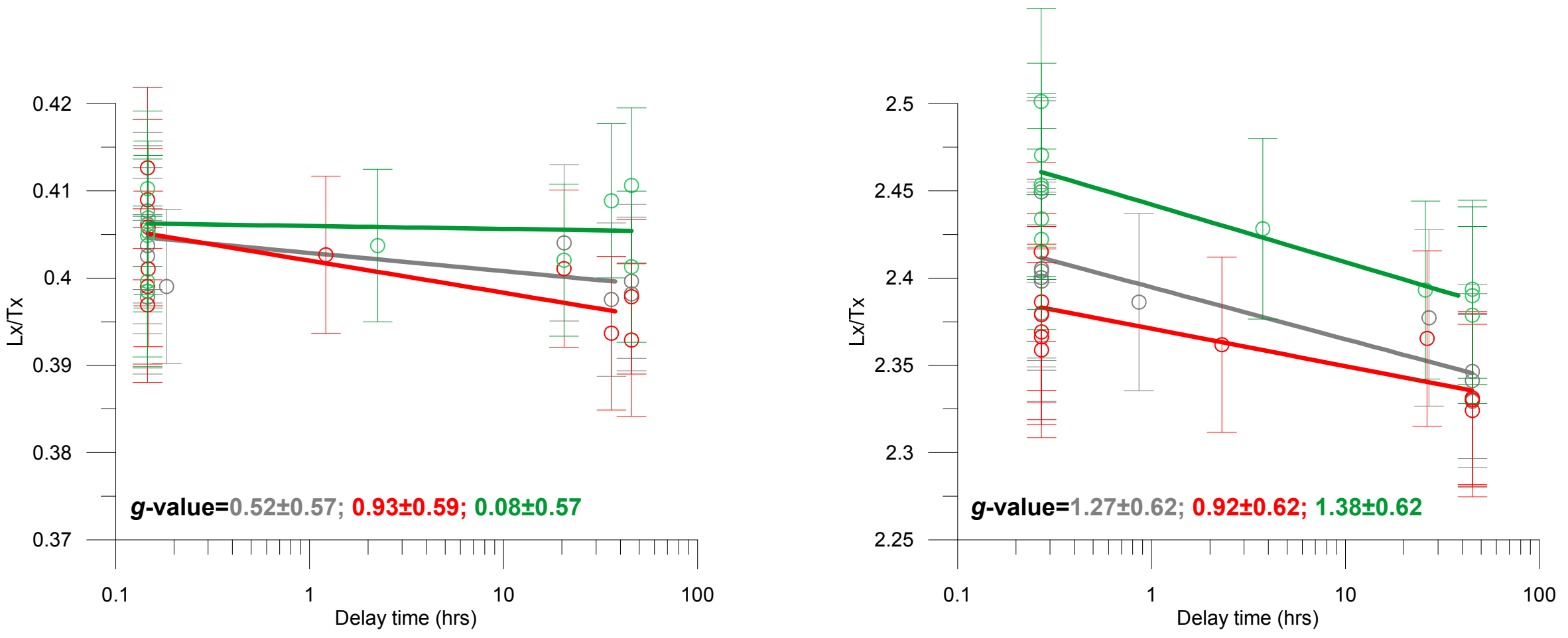
Fig. 6
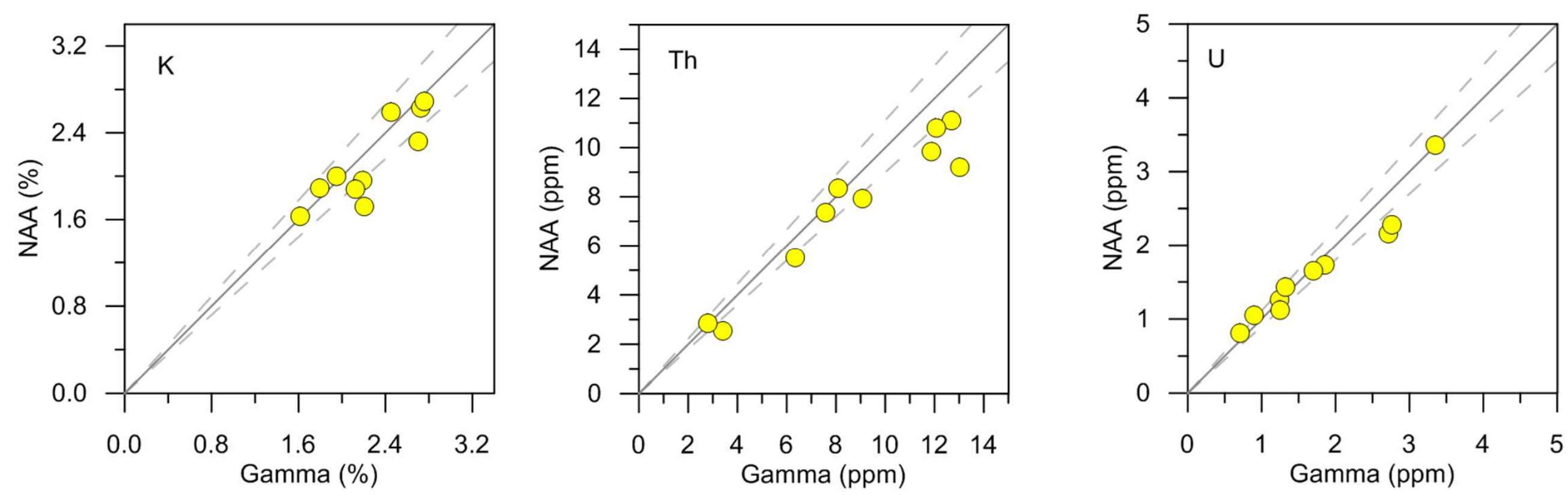
Fig. 7

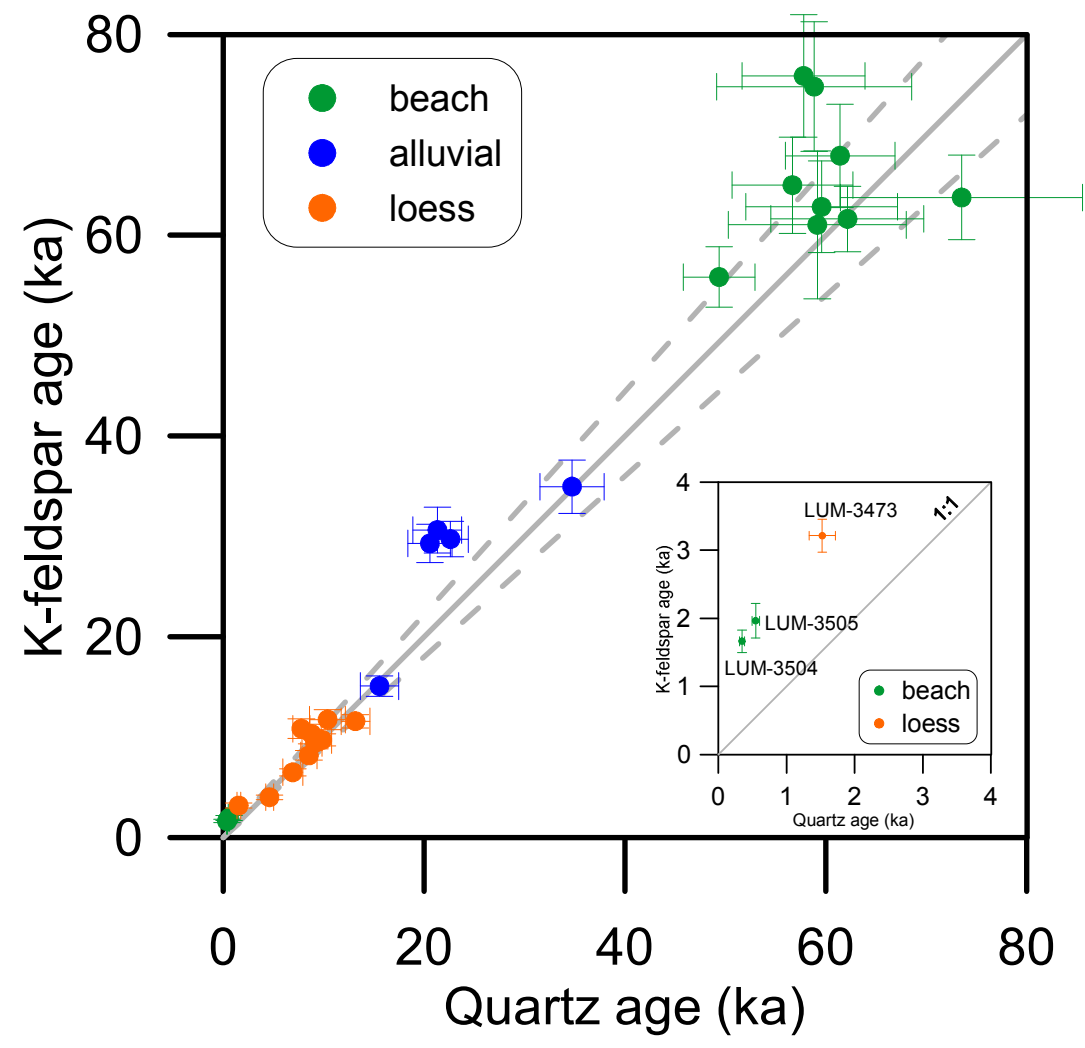




\section{Fig. S1}

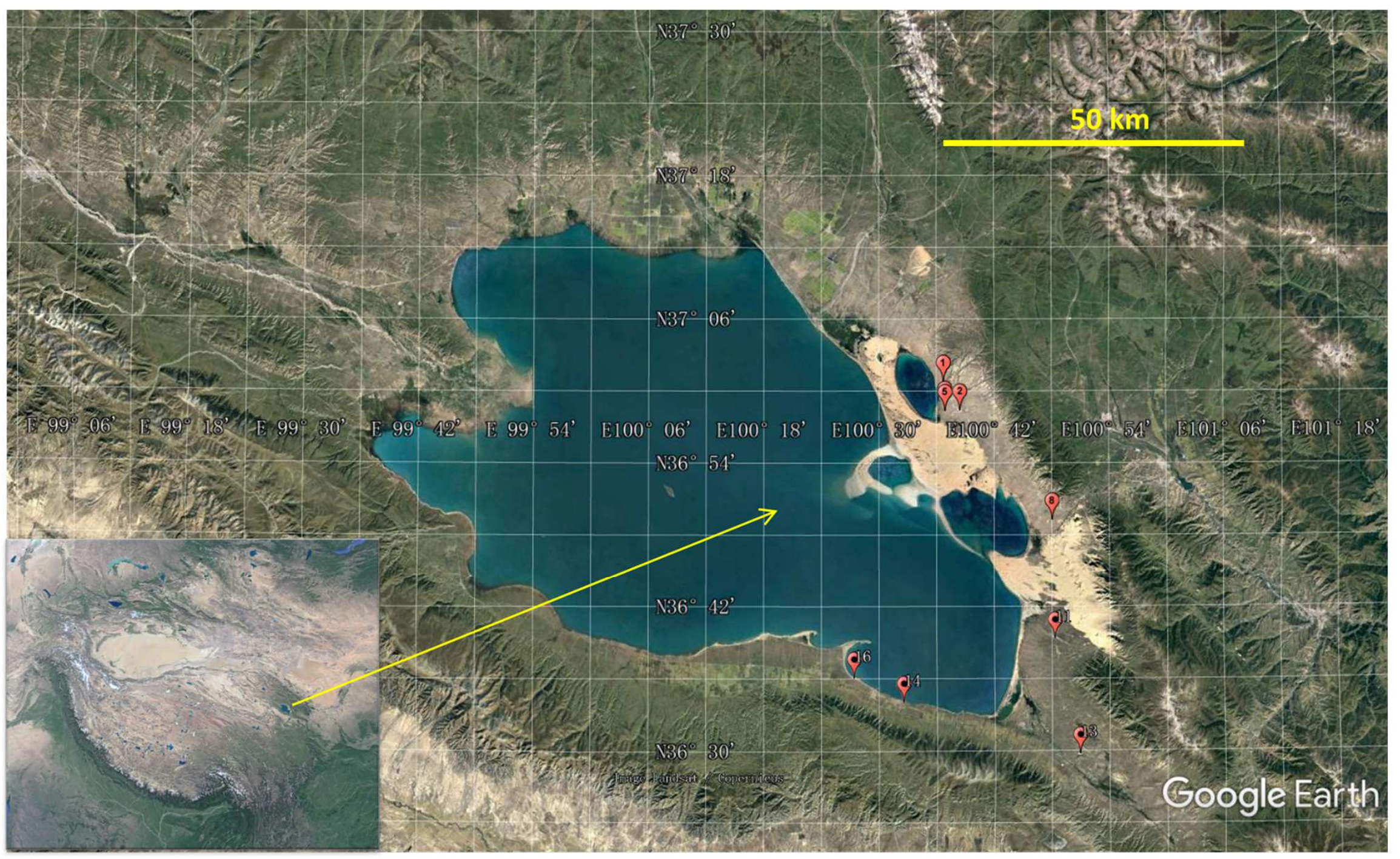


Fig. S2

$$
\text { QH2 }
$$

4

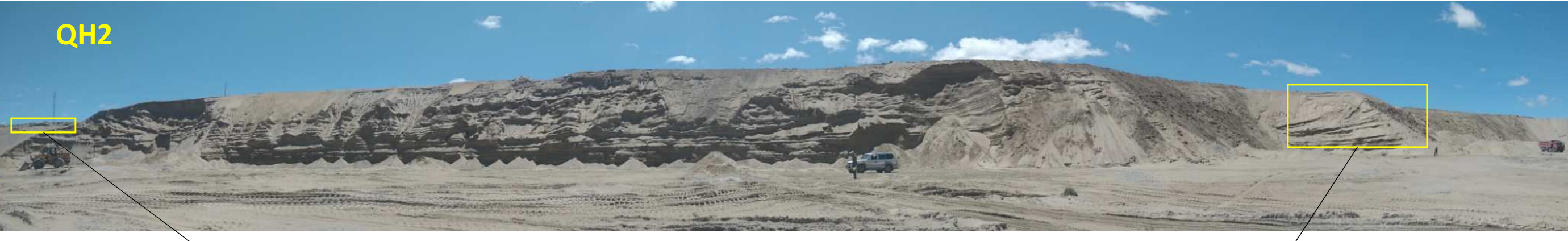
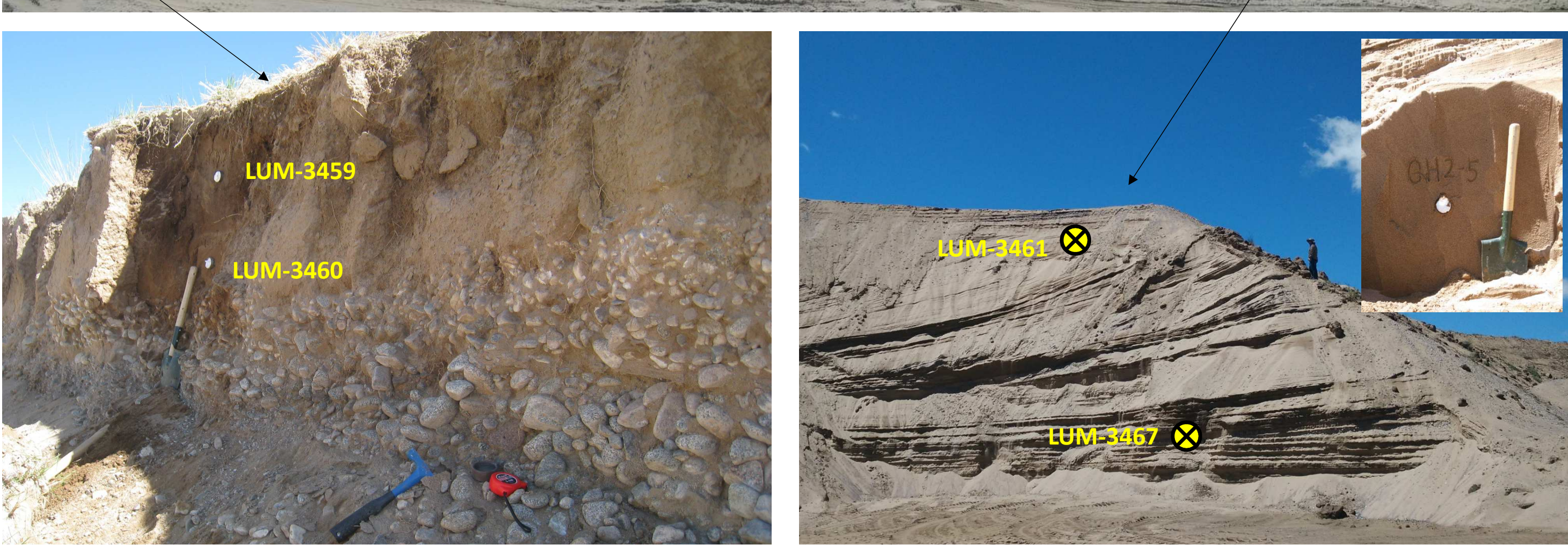


\section{Fig. S3}

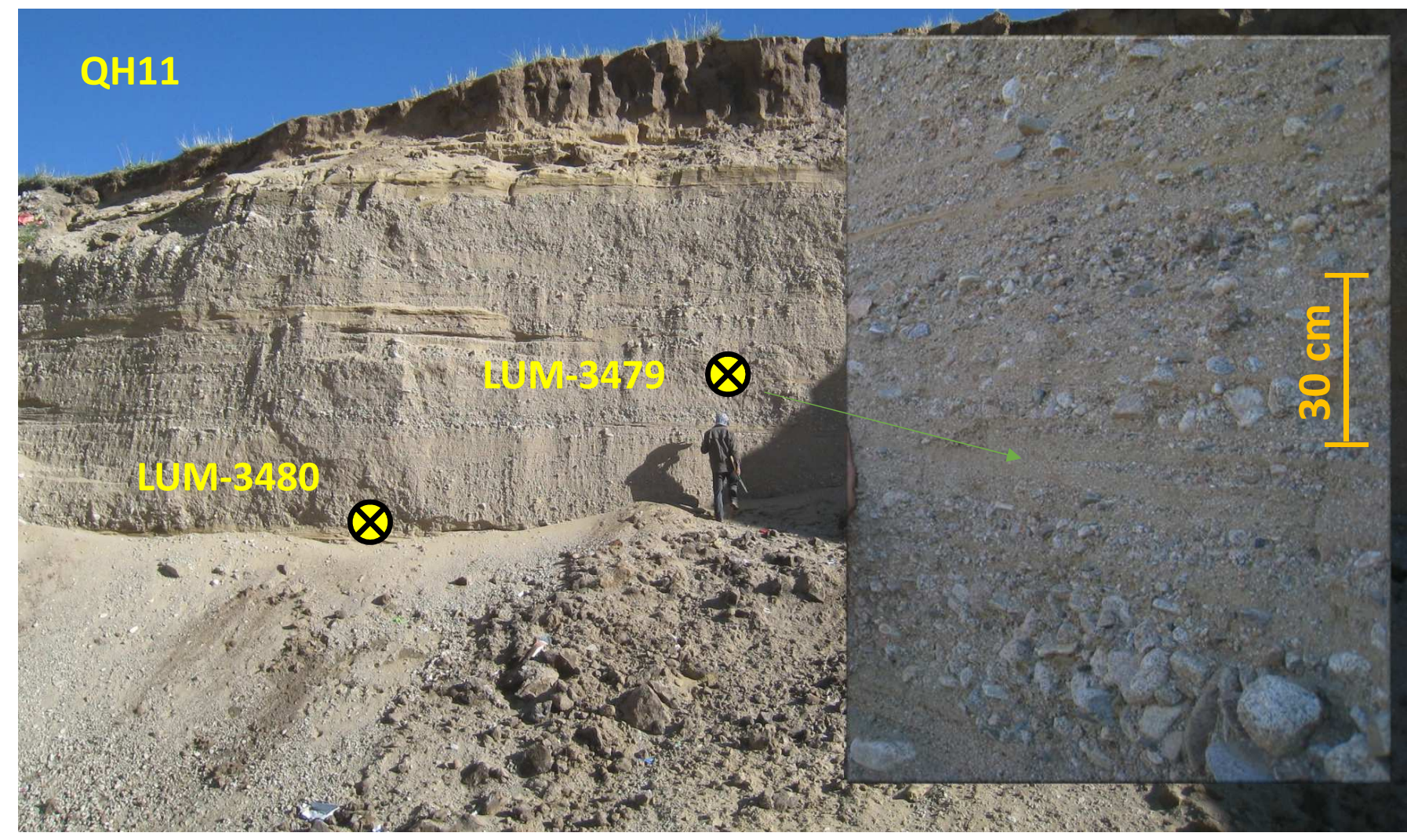


Fig. S4
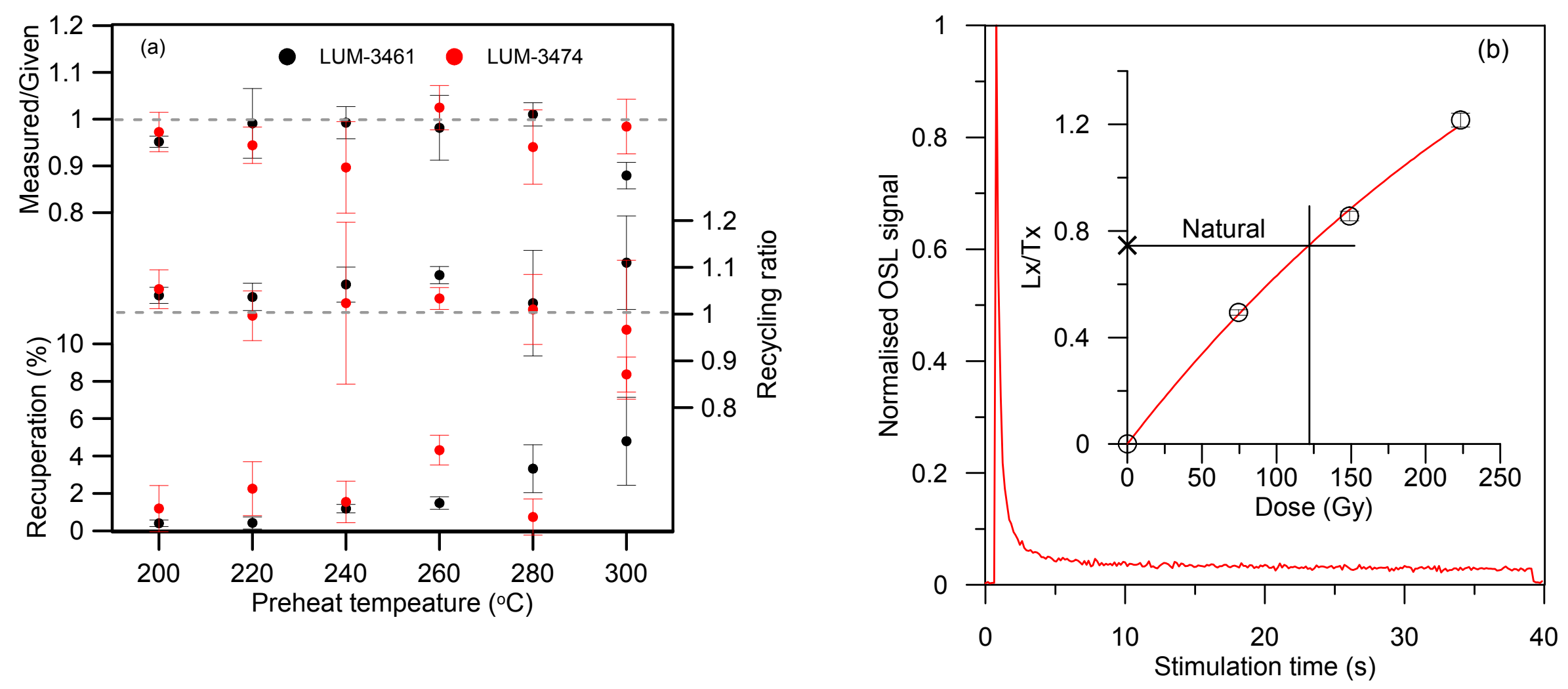
Fig. S5
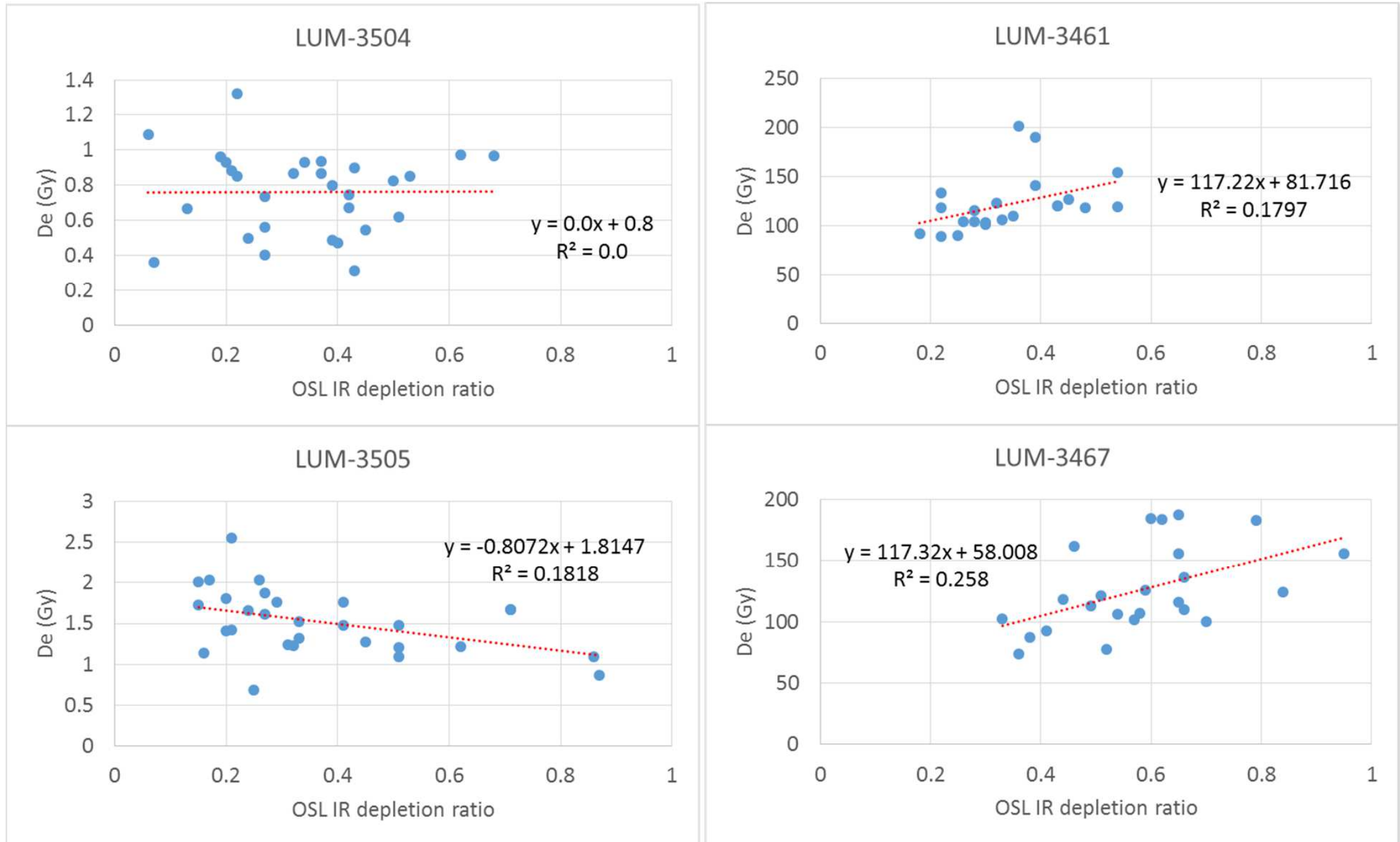
Fig. S6

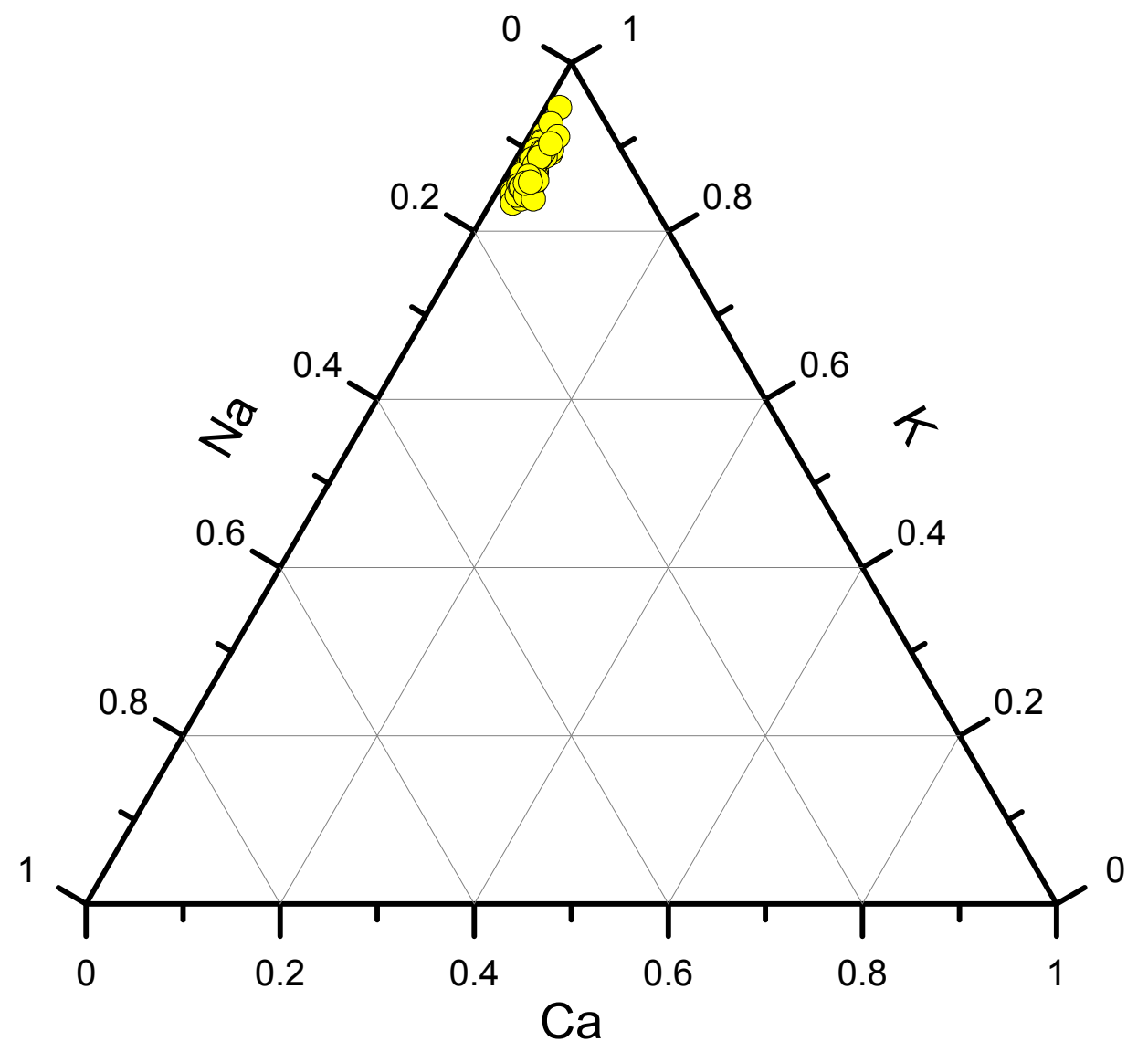




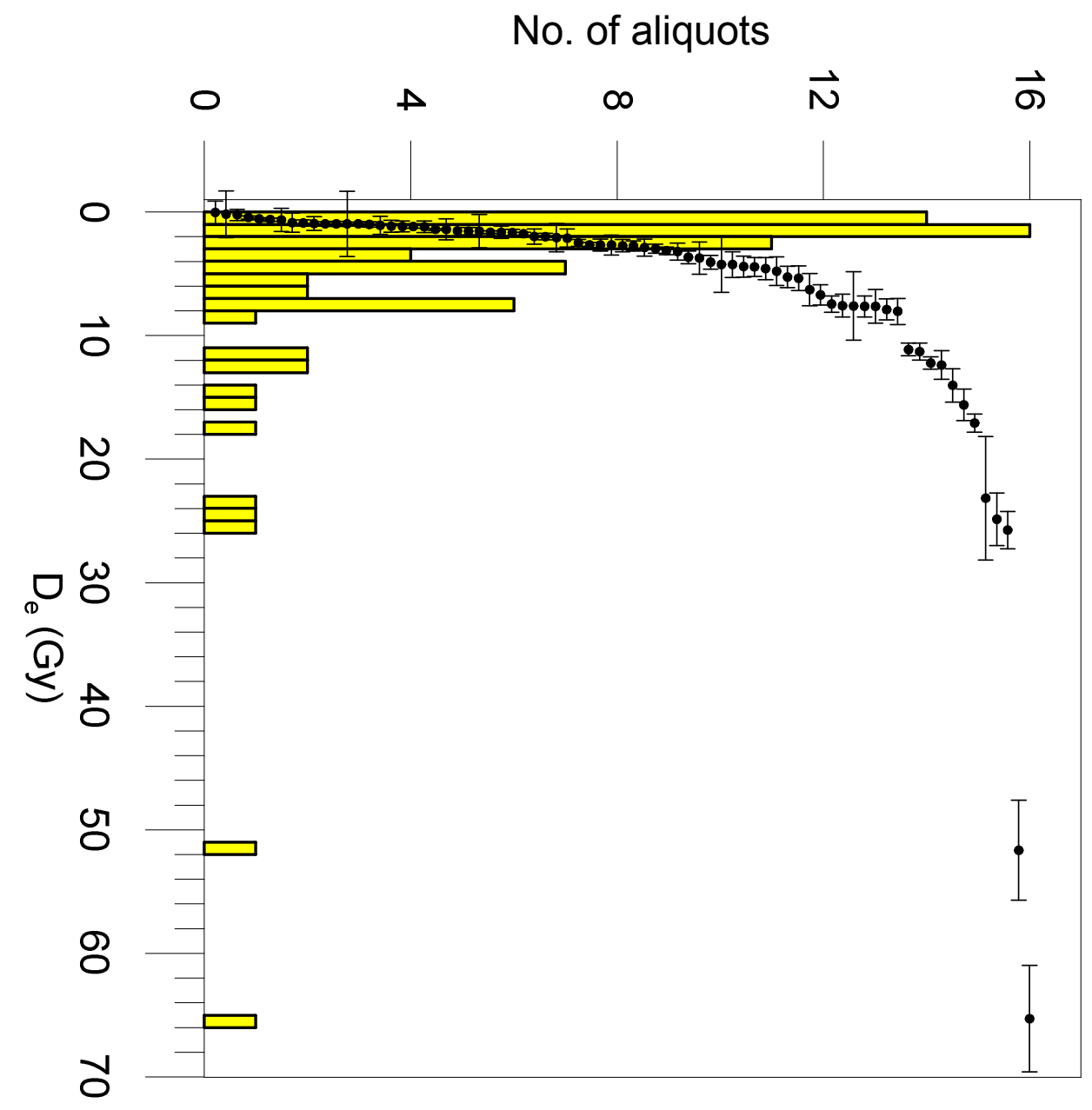


Table S1

\begin{tabular}{|c|c|c|c|c|c|c|c|c|c|c|c|}
\hline Section & $\begin{array}{l}\text { Depositional } \\
\text { environment }\end{array}$ & Sample ID & $\mathrm{U}(\mathrm{ppm})$ & Th (ppm) & K (\%) & $\begin{array}{l}\text { Quartz dose } \\
\text { rate (Gy/ka) }\end{array}$ & $\begin{array}{l}\text { Quartz } D_{e} \\
(\mathrm{~Gy})\end{array}$ & $\begin{array}{l}\text { Quartz age } \\
\text { (ka) }\end{array}$ & $\begin{array}{l}\text { K-feldspar } \\
\text { dose rate } \\
\text { (Gy/ka) }\end{array}$ & $\begin{array}{l}\text { K-feldspar } D_{e} \\
\text { (Gy) }\end{array}$ & $\begin{array}{l}\text { K-feldspar } \\
\text { age (ka) }\end{array}$ \\
\hline \multirow{2}{*}{ QH1 } & Loess & LUM-3457 & $2.74 \pm 0.10$ & $11.7 \pm 0.33$ & $2.21 \pm 0.06$ & $3.5 \pm 0.2$ & $25.2 \pm 1.7$ & $7.1 \pm 0.7$ & $4.3 \pm 0.2$ & $26.2 \pm 0.5$ & $6.1 \pm 0.3$ \\
\hline & Alluvial & LUM-3458 & $1.73 \pm 0.08$ & $7.36 \pm 0.24$ & $1.63 \pm 0.05$ & $2.5 \pm 0.2$ & $39.0 \pm 3.8$ & $15.6 \pm 1.9$ & $3.3 \pm 0.2$ & $49.1 \pm 0.6$ & $15.1 \pm 1$ \\
\hline \multirow{4}{*}{$\mathrm{QH} 2$} & Loess & LUM-3459 & $3.00 \pm 0.11$ & $12.7 \pm 0.36$ & $2.21 \pm 0.06$ & $3.7 \pm 0.2$ & $17.0 \pm 0.9$ & $4.6 \pm 0.4$ & $4.5 \pm 0.2$ & $18.1 \pm 0.3$ & $4 \pm 0.2$ \\
\hline & Loess & LUM-3460 & $2.16 \pm 0.09$ & $9.84 \pm 0.29$ & $1.72 \pm 0.06$ & $2.9 \pm 0.2$ & $26.5 \pm 0.7$ & $9.1 \pm 0.7$ & $3.7 \pm 0.2$ & $34.8 \pm 0.8$ & $9.5 \pm 0.6$ \\
\hline & Beach & LUM-3461 & $0.79 \pm 0.05$ & $3.61 \pm 0.13$ & $1.71 \pm 0.05$ & $2.1 \pm 0.2$ & $121.3 \pm 8.6$ & $56.7 \pm 6.0$ & $2.9 \pm 0.2$ & $190.0 \pm 5.9$ & $65.0 \pm 4.8$ \\
\hline & Beach & LUM-3467 & $0.98 \pm 0.05$ & $5.61 \pm 0.19$ & $1.74 \pm 0.06$ & $2.1 \pm 0.2$ & $126.2 \pm 7.8$ & $58.8 \pm 6.2$ & $2.9 \pm 0.2$ & $213.5 \pm 9.7$ & $74.8 \pm 6.4$ \\
\hline QH5 & Beach & LUM-3468 & $1.26 \pm 0.06$ & $7.93 \pm 0.25$ & $2.59 \pm 0.07$ & $3.3 \pm 0.2$ & $163.8 \pm 4.1$ & $49.4 \pm 3.6$ & $4.0 \pm 0.2$ & $224.6 \pm 1.4$ & $55.8 \pm 3.0$ \\
\hline QH7 & Beach & LUM-3469 & $1.11 \pm 0.06$ & $5.28 \pm 0.18$ & $1.61 \pm 0.05$ & $2.3 \pm 0.2$ & $144.2 \pm 5.9$ & $61.4 \pm 5.5$ & $3.1 \pm 0.2$ & $208.1 \pm 6.6$ & $67.9 \pm 5.2$ \\
\hline \multirow{4}{*}{ QH8 } & Beach & LUM-3472 & $1.42 \pm 0.07$ & $4.38 \pm 0.15$ & $1.32 \pm 0.05$ & $2.0 \pm 0.2$ & $117.7 \pm 7.2$ & $57.8 \pm 6.1$ & $2.8 \pm 0.2$ & $210.2 \pm 5.7$ & $75.9 \pm 6.1$ \\
\hline & Loess & LUM-3473 & $1.32 \pm 0.06$ & $6.32 \pm 0.21$ & $1.46 \pm 0.05$ & $2.3 \pm 0.2$ & $3.5 \pm 0.3$ & $1.5 \pm 0.2$ & $3.0 \pm 0.2$ & $9.8 \pm 0.3$ & $3.2 \pm 0.2$ \\
\hline & Loess & LUM-3474 & $1.69 \pm 0.08$ & $6.58 \pm 0.22$ & $1.50 \pm 0.05$ & $2.4 \pm 0.2$ & $21 \pm 1.6$ & $8.8 \pm 1.0$ & $3.1 \pm 0.2$ & $32.5 \pm 2.1$ & $10.3 \pm 1.0$ \\
\hline & Loess & LUM-3475 & $1.87 \pm 0.08$ & $6.71 \pm 0.22$ & $1.34 \pm 0.05$ & $2.3 \pm 0.2$ & $17.6 \pm 1.3$ & $7.8 \pm 0.9$ & $3.0 \pm 0.2$ & $32.8 \pm 1.8$ & $10.9 \pm 1.0$ \\
\hline \multirow{2}{*}{ QH11 } & Alluvial & LUM-3479 & $1.65 \pm 0.08$ & $11.1 \pm 0.31$ & $2.63 \pm 0.07$ & $3.5 \pm 0.2$ & $79.1 \pm 3.4$ & $22.6 \pm 1.8$ & $4.2 \pm 0.2$ & $125.8 \pm 3.7$ & $29.7 \pm 1.8$ \\
\hline & Alluvial & LUM-3480 & $1.20 \pm 0.06$ & $5.78 \pm 0.20$ & $1.76 \pm 0.06$ & $2.3 \pm 0.2$ & $78.8 \pm 3.2$ & $34.7 \pm 3.2$ & $3.0 \pm 0.2$ & $104.4 \pm 3.1$ & $35 \pm 2.7$ \\
\hline \multirow{6}{*}{ QH13 } & Loess & LUM-3484 & $3.40 \pm 0.12$ & $11.4 \pm 0.32$ & $1.87 \pm 0.06$ & $3.4 \pm 0.2$ & $23.5 \pm 3.0$ & $6.9 \pm 1.0$ & $4.2 \pm 0.2$ & $27.5 \pm 0.2$ & $6.5 \pm 0.4$ \\
\hline & Loess & LUM-3485 & $3.36 \pm 0.12$ & $10.8 \pm 0.30$ & $2.00 \pm 0.06$ & $3.4 \pm 0.2$ & $35.7 \pm 5.6$ & $10.4 \pm 1.8$ & $4.3 \pm 0.2$ & $50.0 \pm 3.3$ & $11.8 \pm 1.0$ \\
\hline & Beach & LUM-3486 & $1.43 \pm 0.07$ & $8.35 \pm 0.25$ & $2.69 \pm 0.08$ & $3.4 \pm 0.2$ & $202.6 \pm 27.1$ & $59.1 \pm 8.9$ & $4.1 \pm 0.2$ & $252.5 \pm 27.4$ & $61.0 \pm 7.4$ \\
\hline & Beach & LUM-3487 & $1.12 \pm 0.06$ & $5.51 \pm 0.19$ & $1.96 \pm 0.06$ & $2.5 \pm 0.2$ & $186.4 \pm 16.9$ & $73.5 \pm 8.8$ & $3.2 \pm 0.2$ & $206.8 \pm 2.9$ & $63.8 \pm 4.2$ \\
\hline & Beach & LUM-3488 & $1.08 \pm 0.06$ & $5.46 \pm 0.19$ & $1.98 \pm 0.06$ & $2.5 \pm 0.2$ & $151.4 \pm 15.2$ & $59.6 \pm 7.6$ & $3.2 \pm 0.2$ & $204.1 \pm 6.7$ & $62.8 \pm 4.6$ \\
\hline & Beach & LUM-3489 & $1.32 \pm 0.06$ & $7.86 \pm 0.24$ & $2.78 \pm 0.08$ & $3.5 \pm 0.2$ & $214.7 \pm 21.9$ & $62.2 \pm 7.6$ & $4.2 \pm 0.2$ & $256.2 \pm 2.2$ & $61.6 \pm 3.2$ \\
\hline \multirow{4}{*}{ QH14 } & Loess & LUM-3490 & $2.40 \pm 0.10$ & $11.1 \pm 0.31$ & $1.97 \pm 0.06$ & $3.2 \pm 0.2$ & $27.1 \pm 1.8$ & $8.5 \pm 0.8$ & $4.0 \pm 0.2$ & $32.5 \pm 0.6$ & $8.2 \pm 0.5$ \\
\hline & Loess & LUM-3491 & $2.75 \pm 0.10$ & $12.0 \pm 0.34$ & $1.93 \pm 0.06$ & $3.2 \pm 0.2$ & $42.6 \pm 3.6$ & $13.1 \pm 1.4$ & $4.0 \pm 0.2$ & $46.8 \pm 0.3$ & $11.6 \pm 0.7$ \\
\hline & Alluvial & LUM-3492 & $2.45 \pm 0.10$ & $11.8 \pm 0.33$ & $2.38 \pm 0.07$ & $3.5 \pm 0.2$ & $72.7 \pm 6.0$ & $20.6 \pm 2.2$ & $4.3 \pm 0.2$ & $126.2 \pm 4.8$ & $29.3 \pm 1.9$ \\
\hline & Alluvial & LUM-3493 & $2.28 \pm 0.09$ & $9.20 \pm 0.27$ & $1.88 \pm 0.06$ & $2.9 \pm 0.2$ & $61.0 \pm 5.3$ & $21.3 \pm 2.4$ & $3.6 \pm 0.2$ & $111.3 \pm 4.8$ & $30.6 \pm 2.3$ \\
\hline \multirow{2}{*}{ QH16 } & Beach & LUM-3504 & $1.05 \pm 0.05$ & $2.54 \pm 0.10$ & $1.89 \pm 0.06$ & $2.4 \pm 0.2$ & $0.8 \pm 0.1$ & $0.3 \pm 0.1$ & $3.1 \pm 0.2$ & $5.1 \pm 0.4$ & $1.7 \pm 0.2$ \\
\hline & Beach & LUM-3505 & $0.81 \pm 0.05$ & $2.85 \pm 0.11$ & $2.32+0.07$ & $2.7 \pm 0.2$ & $1.5 \pm 0.1$ & $0.5 \pm 0.1$ & $3.4 \pm 0.2$ & $6.6 \pm 0.7$ & $2.0 \pm 0.3$ \\
\hline
\end{tabular}

